\title{
A UNIVERSIDADE DO VALE DO PARAÍBA COMO PATRIMÔNIO DA CIDADE DE SÃO JOSÉ DOS CAMPOS
}

\author{
Maria Helena Alves da Silva' \\ Maria Aparecida Chaves Ribeiro Papali ${ }^{2}$ \\ Antônio Carlos Machado Guimarães ${ }^{3}$
}

\begin{abstract}
Resumo: Este trabalho tem como objetivo explorar a visão da UNIVAP - Universidade do Vale do Paraíba como um patrimônio da cidade de São José dos Campos pelos seus alunos e funcionários, explorando o vínculo entre a cidade e a Universidade, quais são os critérios necessários para que ela seja vista como um patrimônio da cidade e, principalmente, se ela é percebida como um patrimônio. Para a realização da pesquisa, foram utilizados diversas publicações acerca da relação cidade-universidade, além de conceitos de patrimônio revisão bibliográfica e história oral, onde serão utilizados os depoimentos do CEHVAP Centro de História da UNIVAP.

Palavras-chave: Patrimônio; Universidade; Vale do Paraíba; Universidade do Vale do Paraíba.
\end{abstract}

\footnotetext{
1 Graduada em História, mestranda do programa de Planejamento Urbano e Regional da Universidade do Vale do Paraíba, Brasil. E-mail: cehvap@univap.br.

2 UNIVAP/PLUR - Programa de Planejamento Urbano e Regional, Brasil. E-mail: papali@univap.br.

3 UNIVAP/PLUR - Programa de Planejamento Urbano e Regional, Brasil. E-mail: guimaraes@univap.br.
} 